Article

\title{
A Curcumin Analog Exhibits Multiple Biologic Effects on the Pathogenesis of Alzheimer's Disease and Improves Behavior, Inflammation, and $\beta$-Amyloid Accumulation in a Mouse Model
}

\author{
Ih-Jen Su ${ }^{1,2, *}$, Hong-Yi Chang ${ }^{1}$, Hui-Chen Wang ${ }^{2}$ and Kuen-Jer Tsai ${ }^{3,4, * \mathbb{C}}$ \\ 1 Department of Biotechnology and Food Technology, Southern Taiwan University of Science and Technology, \\ Tainan 71005, Taiwan; czeus1974@gmail.com \\ 2 Merry Life Biomedical Company, Tainan 71005, Taiwan; sabrinawang@tmlbio.com \\ 3 Institute of Clinical Medicine, College of Medicine, National Cheng Kung University, Tainan 704, Taiwan \\ 4 Research Center of Clinical Medicine, National Cheng Kung University Hospital, College of Medicine, \\ National Cheng Kung University, Tainan 704, Taiwan \\ * Correspondence: suihjen0704@stust.edu.tw (I.-J.S.); kjtsai@mail.ncku.edu.tw (K.-J.T.); \\ Tel.: +886-6-2353535-4254 (I.-J.S.)
}

Received: 9 June 2020; Accepted: 28 July 2020; Published: 30 July 2020

\begin{abstract}
Drugs for the treatment of Alzheimer's disease (AD) are in urgent demand due to the unmet need and the social burden associated with the disease. Curcumin has been historically considered as a beneficial product for anti-aging and AD. However, many efforts to develop curcumin for clinical use are hindered mainly due to its poor bioavailability. Recent development in drug delivery and structural design has resolved these issues. In this study, we identified a small molecule, TML-6, as a potential drug candidate for $\mathrm{AD}$ through screening a panel of curcumin derivatives using six biomarker platforms related to aging biology and AD pathogenesis. The structural modification of TML-6 is designed to improve the stability and metabolism of curcumin. Cell biological studies demonstrated that TML- 6 could inhibit the synthesis of the $\beta$-amyloid precursor protein and $\beta$-amyloid (A $\beta$ ), upregulate Apo E, suppress NF- $\mathrm{kB}$ and mTOR, and increase the activity of the anti-oxidative Nrf2 gene. In the 3x-Tg AD animal model, TML-6 treatment resulted in significant improvement in learning, suppression of the microglial activation marker Iba-1, and reduction in $A \beta$ in the brain. Although TML-6 exhibited a greater improvement in bioavailability as compared to curcumin, formulation optimization and toxicological studies are under development to assure its druggability. Taken together, TML- 6 meets the current strategy to develop therapeutics for AD, targeting the combination of the $A \beta$ cascade and aging-related biology processes.
\end{abstract}

Keywords: Alzheimer's disease therapy; curcumin analog; TML-6; aging; bioavailability

\section{Introduction}

Alzheimer's disease (AD) is the most common cause of dementia. It has been estimated that the total number of AD individuals will increase to approximately 74.7 million by 2030 and the cost of healthcare will increase to USD 1 trillion annually by 2050 [1]. More than hundreds of clinical trials have been conducted in the AD field in the past decades [2], however, only a few symptom-relief agents reach the markets. This is mainly due to the inadequate understanding of the complex pathogenesis of $\mathrm{AD}$, the inappropriate design of clinical trials, and the lack of reliable diagnostic tests or biomarkers for patient inclusion [3]. Thus, there exists an urgent demand for developing therapeutic drugs for AD patients to delay and arrest the disease progression, or even to reverse the cognitive function decline, especially for patients at the non-demented or early stage disease. 
The dominant $\mathrm{AD}$ pathogenesis theory is the accumulation of $\mathrm{A} \beta$ and Tau proteins in the patient's brain [4]. The senile plaques in $\mathrm{AD}$ are composed of $\mathrm{A} \beta$ fibrillary proteins which promote Tau hyper-phosphorylation, neuron cell death, cognitive dysfunction and finally disruption of normal brain function [5-7]. The A $\beta$ peptide is composed of 40-42 amino acids and generated by proteolytic processing of the larger amyloid precursor protein (APP), which produces $A \beta$ by the cleavage of paired enzymes $\beta$-secretase and $\gamma$-secretase [8]. Therefore, the drug development initiatives in the past decades have mainly targeted $A \beta$, tau, and the secretase [2,9]. Unluckily, the majority of clinical trials in the past decade were unsuccessful, many of which failed or withdrew in the late stage trials $[2,3,10]$. Most recently, the clinical trials using anti-A $\beta$ monoclonal antibodies to prevent $A \beta$ aggregation or degrade $A \beta$ aggregates resulted in disappointing outcomes [3,11]. In May 2018, the US National Institutes of Health organized an expert summit to discuss the strategy to develop preventive and therapeutic measures for AD control, and recommended that novel mechanistic insight and precision medicine must be enabled to clearly understand the multifaceted pathogenesis of $\mathrm{AD}$, and to develop drugs targeting at combining the $\mathrm{A} \beta$ cascade and other disease-modifying pathways of $\mathrm{AD}$ [12].

Besides the dominant APP/A $\beta /$ tau hypothesis, several alternate mechanisms or disease-modifying pathways of $\mathrm{AD}$ pathogenesis have been proposed. Among them, apo-lipoprotein $\mathrm{E}$ (Apo E) represents one important factor in $\mathrm{AD}$ pathogenesis. ApoE plays a major role in cholesterol biology and is also involved in the catabolism of $A \beta$ clearance [13]. Genetic studies have indicated that the polymorphism of the ApoE isoform $\varepsilon 4$ is a greater risk factor in comparison with isoforms $\varepsilon 2$ and $\varepsilon 3$ for late-onset $\mathrm{AD}$ [14]. Although several mechanisms associated with ApoE-related AD have been reported, the exact role of ApoE in AD pathogenesis remains to be clarified [14]. In AD patients, the ApoE levels in plasma tend to be lower than healthy individuals as observed in cohort and meta-analysis studies $[15,16]$. Therefore, targeting at ApoE in all APOE genotypes may provide a strategy for the treatment of AD.

Lately, neuro-inflammation and the autophagy machinery dysfunction are among the most notable AD pathogenesis. Neuro-inflammation associated with $A \beta$ accumulation and microglial activation has been found to play a critical role in AD progression $[17,18]$. Patients with rheumatoid arthritis receiving long-term treatment of nonsteroidal anti-inflammatory drugs showed protective effects on AD and had an approximately 50\% reduction in the risk of AD development [19]. Dysfunction of the autophagy machinery and the activation of anti-aging mTOR has been reported to cause the enhancement of $\mathrm{A} \beta$ production and deposition through APP proteolysis by upregulating $\beta$ - and $\gamma$-secretases [20]. Therefore, the suppression of mTOR phosphorylation may provide a therapeutic strategy for AD.

The most provocative theory related to $\mathrm{AD}$ pathogenesis recently proposed is the role of oxidative stress and free radicals associated with the aging process [21,22]. The production of free radicals during oxidative stress could result in the impairment of DNA repair and cause protein mutations and lipid peroxidation, which is strongly implicated in aging-related diseases and AD [22]. The activation of the Nrf2-mediated antioxidant system has been proposed as an important strategy to downregulate oxidative stress and is also related to the pathogenesis in $\mathrm{AD}$ [23]. Antioxidant or anti-NrF2 medication at the early stages of the disease may hence provide prevention of AD. Therefore, efforts to develop a drug with multifaceted functions or to combine drugs that target the combination of the $A \beta$ cascade and aging-related biologic pathways will constitute the novel strategy to develop drugs for $\mathrm{AD}$ treatment.

Herbs and natural compounds have been found to exhibit diverse biological and medical functions throughout the medical history [24,25]. Curcumin is among one of the most attractive compounds that serve as a candidate for anti-aging and AD therapy, owing to the low prevalence of AD in India where curcumin is included in the daily diet $[25,26]$. Curcumin has been effective against a wide variety of aging-related diseases through multiple molecular mechanisms [26-30]. Several studies have indicated that curcumin has neuroprotective and cognitive-improving potential which could prevent AD and other neurodegenerative diseases [31,32]. Despite ample scientific reports supporting the biological functions of curcumin in human diseases, a huge controversy exists regarding curcumin's capability as a drug, mainly due to the broad or nonspecific interaction with target molecules [33,34] and its poor bioavailability [35]. Nevertheless, the recent development of formulation technology and structural 
modification of curcumin have solved this problem. The most recent progress of curcumin in AD clinical trial is a double-blind, placebo-controlled 18-month trial conducted by Gary Small and his group at University of California, Los Angeles (UCLA), which showed therapeutic effects on memory and reduction in brain amyloid in non-demented adults by the administration of a bioavailable form of curcumin [36]. This report provides the first proof of concept in the development of curcumin for $\mathrm{AD}$ prevention and therapy using the current $\mathrm{AD}$ biomarkers.

In this study, we identified TML- 6 as a potential AD drug candidate based on the evidence including: (I) cell biology characterization through screening a library of curcumin analogs using biomarker technology, which includes the key factors related to aging biology and AD pathogenesis as mentioned above; (II) using a triplex transgenic AD mouse model to verify the in vitro biologic effects of TML-6; (III) pharmacokinetic studies of TML-6 to evaluate the feasibility of TML-6 for future drug development. TML- 6 was found to effectively inhibit multiple pathways of AD pathogenesis, including the inhibition of the synthesis of APP and $A \beta$, the upregulation of levels of ApoE, the suppression of the inflammation-related phosphorylated NF- $\mathrm{KB}$ and the aging-related $\mathrm{mTOR}$, and the increase in the expression of the anti-oxidative stress gene Nrf2. In the triplex AD transgenic animal study, TML-6 could improve the memory behavior in the Morris water maze test, suppress microglial activation, and reduce the brain levels of A $\beta$. TML- 6 displayed greatly improved pharmacokinetic readouts as compared to traditional curcumin. In summary, we propose TML- 6 as a potential AD drug candidate which meets the current strategy to develop drugs targeting the combination of the $A \beta$ cascade and aging-related biologic pathways for AD. All the cell biology studies, pharmacokinetic studies, and $\mathrm{AD}$ transgenic mouse studies were conducted using unformulated TML-6. Formulation optimization is under development before the preclinical toxicology is conducted.

\section{Results}

\subsection{Structural and Physico-Chemical Characterization of TML-6}

As compared to the orange to yellow color of curcumin, TML-6 has a light yellowish to white color. A comparison of the chemical structures of curcumin and TML-6 is shown (Figure 1A,B), respectively. The two hydroxyl groups on curcumin's benzene structure are hot spots for $\beta$-glucuronidation and are replaced by methoxyl groups in TML- 6 to slow down the metabolism. Furthermore, the structure of TML-6 has fixed the isomerization which is more stable in acidic $\mathrm{pH}$ than curcumin. Therefore, by structure design and prediction analysis, TML-6 will slow down the metabolism and become more stable under the acidic or basic condition than curcumin. In the beginning, a total of twelve curcumin derivatives were conducted to screen their therapeutic potential. Based on chemical prediction and cell biological characterization, two curcumin analogs remained. TML-6 was finally chosen as a candidate because the other one had high cytotoxicity.

In preliminary studies, the water solubility of curcumin and TML- 6 was less than $0.1 \mathrm{mg} / \mathrm{mL}$ for both. TML-6 exhibited a higher degree of lipophilicity, which makes it a feature of poor water solubility. In brain penetration studies, TML-6 fed at an oral dose of $150 \mathrm{mg} / \mathrm{kg}$ could be detected at a level of $3 \mathrm{ng} / \mathrm{mL}$ ( $10 \%$ of the plasma pharmacokinetics (pK) levels) in the AD transgenic mouse brain. However, TML- 6 could not be detected in the normal mouse brain at the same dose. The data are interesting and raise the possibility of the dysfunction or leakage of blood-brain barrier (BBB) in AD mice. We are designing a study to clarify the BBB penetration after feeding TML- 6 to normal and AD mice at different ages.

To evaluate whether TML- 6 can be developed as a therapeutic drug for AD, the following three categories of studies were further conducted: (I) cell biology of aging and AD-related biomarker studies; (II) the efficacy of TML-6 in the triplex AD transgenic mouse model; and (III) pharmacokinetic studies of curcumin and TML-6. The results are shown in the following sections. 
(A)

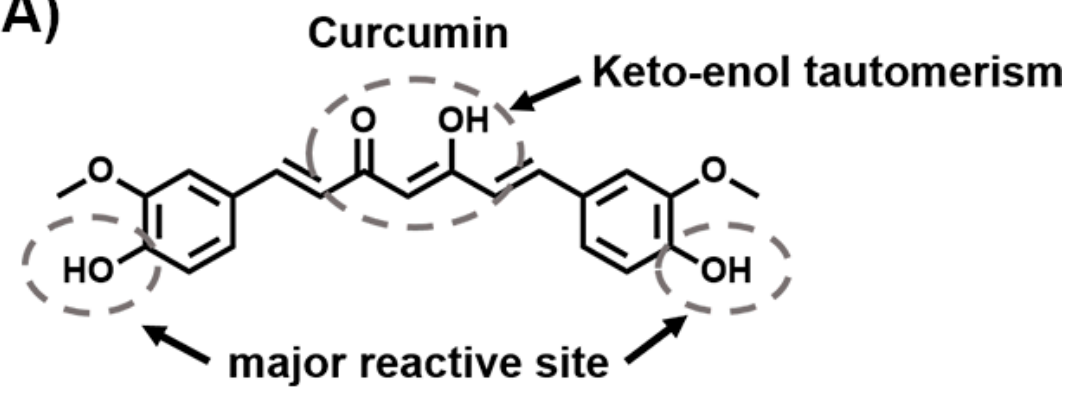

(B)

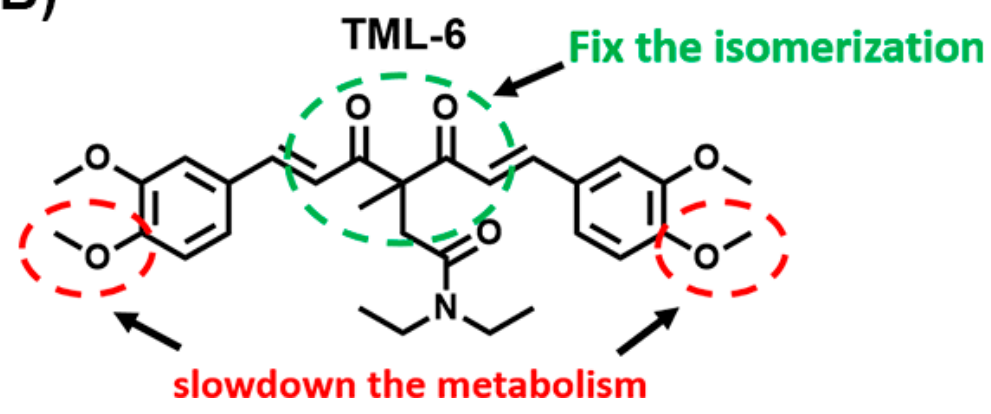

Figure 1. Comparison of traditional curcumin and TML-6 through its chemical structure. (A) The medical use of traditional curcumin is limited by its water insolubility (hydrophobic), low intestinal absorption, rapid metabolism, which leads to poor bioavailability. (B) TML-6 modified from traditional curcumin conserves the bioactivity of curcumin, becomes more stable, and slows down in metabolism. However, preliminary studies revealed that both curcumin and TML-6 had poor water solubility and need to be optimized by formulation.

\subsection{Cell Biologic Characterization of TML-6}

\subsubsection{Cytotoxicity of TML-6 Examined by Cell Counting Kit-8 (CCK-8)}

The cell viability of TML- 6 was examined by CCK- 8 in Huh-7 cell line for $24 \mathrm{~h}$ incubation and the working concentration was indicated (Figure 2A). The data from the CCK-8 assay showed that TML-6 revealed no cytotoxicity in Huh-7 cells at concentrations below $5 \mu \mathrm{M}$ (equivalent to $2.61 \mu \mathrm{g} / \mathrm{mL}$ ). The concentration was expressed in molarity and $\mathrm{ng} / \mathrm{mL}$, as indicated (Figure 2A). For practical use in drug development, the concentration was expressed in $\mathrm{ng} / \mathrm{mL}$ in the following studies. The half maximal inhibitory concentration (IC50) value of TML-6 in Huh-7 cells at $4.19 \mu \mathrm{g} / \mathrm{mL}(8 \mu \mathrm{M})$. However, there was no obvious cytotoxicity of traditional curcumin, despite the highest concentration of $20 \mu \mathrm{g} / \mathrm{mL}$ used in this study (Figure 2A).

\subsubsection{TML-6 Could Ameliorate the Antioxidative and Anti-Aging Effect through Transcriptional} Activation of the Nrf2 Gene

The activation of the Nrf2-mediated antioxidant system has been proposed as an important strategy to downregulate oxidative stress and is also related to the pathogenesis of anti-aging and AD [23]. To verify whether TML-6 could exhibit antioxidant activity, we studied the transcriptional activity of the Nrf2 gene promoter after treating with TML-6, using the luciferase reporter assay. Our data showed that TML- 6 could exhibit transcriptional activation of the Nrf2 gene in a dose-dependent manner, with the highest activity at a concentration of $1.32 \mu \mathrm{g} / \mathrm{mL}$, which was 12.1- and 6.6-fold stronger than the traditional curcumin at a dose of 10 and $20 \mu \mathrm{g} / \mathrm{mL}$, respectively (Figure 2B). As shown in Figure 2B, the cytotoxicity was found at a higher concentration (beyond $5.24 \mu \mathrm{g} / \mathrm{mL}$ ) of TML- 6 when transiently transected with the Nrf2 promoter into Huh-7 cells. 

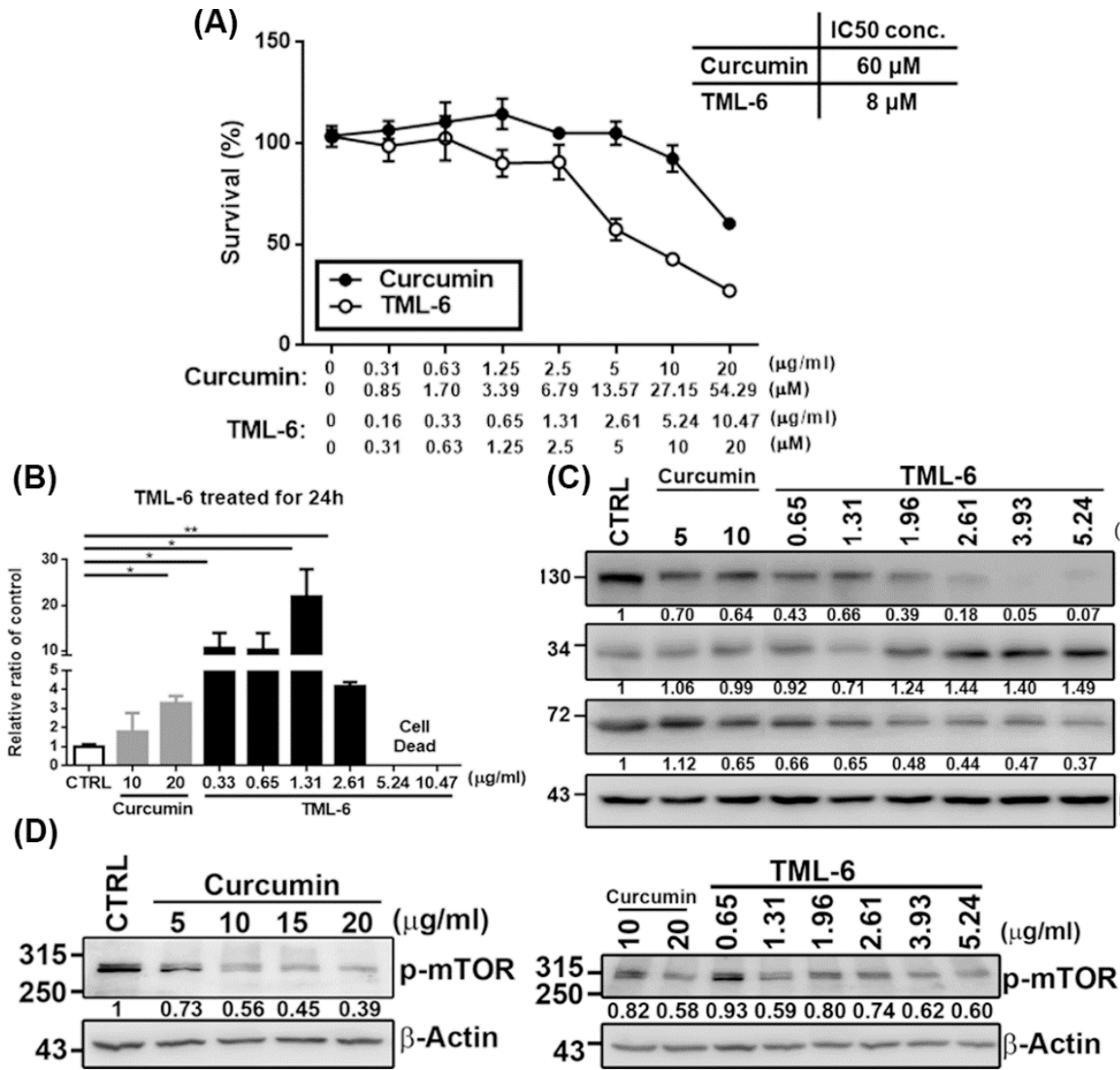

Figure 2. The cytotoxicity studies, inhibitory concentration (IC)50, and biologic studies of TML-6. TML-6 could transcriptionally activate the Nrf2 promoter, suppress the expression of the amyloid precursor protein (APP) and phospho-NF- $\mathrm{KB}$, and in contrast, increases the ApoE and phospho-mTOR expression in Huh-7 cell line. (A) The cytotoxicity (IC50 assay) of traditional curcumin and TML-6 were examined by CCK-8 in Huh-7 cells for $24 \mathrm{~h}$. The working concentration of traditional curcumin and TML- 6 was expressed in $\mu \mathrm{M}$ and $\mu \mathrm{g} / \mathrm{mL}$ separately for comparison. The IC50 of curcumin and TML-6, 60 and $8 \mu \mathrm{M}$, respectively, is expressed at the right side of Figure 2A. In the following studies, the dose concentration was expressed in $\mu \mathrm{g} / \mathrm{mL}$ only, as indicated in Figure 2B-D. (B) The luciferase plasmid contains the Nrf2 promoter co-transfected with pRL-TK (Renilla) into Huh-7 cells by Lipofectamine 2000. Transfected cells were treated with curcumin and TML- 6 for $24 \mathrm{~h}$, and the Nrf2 promoter activity was analyzed by the Dual-Luciferase Report assay system. TML-6 could exhibit transcriptional activation of the Nrf2 gene in a dose-dependent manner, with the highest activity at a concentration of $1.32 \mu \mathrm{g} / \mathrm{mL}$, which was 12.1- and 6.6-fold stronger than the traditional curcumin at a dose of 10 and $20 \mu \mathrm{g} / \mathrm{mL}$, respectively. Data represent the mean with a standard deviation (SD) error bar and $p$ value $<0.05$ was considered significant $\left({ }^{*} p<0.05,{ }^{* *} p<0.01\right)$. The Nrf2 promoter plasmid revealed a higher cytotoxicity beyond $5.24 \mu \mathrm{g} / \mathrm{mL}$. (C) Huh-7 cells were treated with different doses of traditional curcumin and TML-6 for $24 \mathrm{~h}$. Western blotting was performed to examine Alzheimer's-related protein molecules such as APP, Apo E, inflammatory marker-phosphorylated NF- $\mathrm{B}$ (C), and phosphorylated mTOR (D). The quantification of protein expression levels in APP, ApoE, p-NFkB and p-mTOR were normalized by $\beta$-Actin and are shown as fold induction in comparison to the untreated control (CTRL) under immunoblotting data in each panel. These AD biomarker proteins revealed a dose-dependent manner in response to TML-6 treatment. 
2.2.3. TML-6 Exhibited Multiple Biologic Effects on AD-Related Biomarkers in Protein Levels, including APP (Amyloid Precursor Protein), Apo E, and Phospho-NF-kB

To examine the protein expression levels of AD-related biomarkers, Huh-7 cells were treated with traditional curcumin and TML- 6 for $24 \mathrm{~h}$, followed by Western blotting analysis. Our result indicated that the protein expression levels of APP and phospho-NF- $\mathrm{kB}$ exhibited a dose-dependent reduction after treating with TML- 6 for $24 \mathrm{~h}$. TML- 6 reduced the APP protein expression level by $60 \%$ at a dose of $1.96 \mu \mathrm{g} / \mathrm{mL}$ after $24 \mathrm{~h}$ treatment, whereas traditional curcumin reduced the APP level by $30 \%$ at a dose of $5 \mu \mathrm{g} / \mathrm{mL}$ compared with the medium control (Figure 2C). TML-6 also decreased the level of phosphorylated NF- $\mathrm{kB}$ by about $50 \%$ at a dose of $1.96 \mu \mathrm{g} / \mathrm{mL}$ after $24 \mathrm{~h}$ treatment, while traditional curcumin decreased the level of phosphorylated NF- $\mathrm{kB}$ by $35 \%$ at a dose of $10 \mu \mathrm{g} / \mathrm{mL}$ compared with the medium control (Figure 2C). On the other hand, the protein expression levels of ApoE were significantly increased after TML- 6 treatment. The Western blotting data indicated that TML- 6 could induce the protein expression level of ApoE by approximately $44 \%$ at a dose of $2.62 \mu \mathrm{g} / \mathrm{mL}$ compared to both the medium and curcumin control (Figure 2C).

\subsubsection{TML-6 Inhibits the mTOR Signaling Pathway through the Suppression of Phospho-mTOR}

Recent studies reported that mTOR signaling pathway links to the aging-dependent cognitive decline and acts as a critical effector of cerebrovascular dysfunction in $\mathrm{AD}[37,38]$. On the other hand, the activation of mTOR enhances $A \beta$ production and also leads to autophagy dysfunction in the aging process, which results in the disruption of $A \beta$ clearance and increases $A \beta$ deposition [39]. Therefore, the inhibition of phospho-mTOR may not only extend life span but also provide a therapeutic strategy against AD. In this study, Huh-7 cells were treated with traditional curcumin and TML-6 for $24 \mathrm{~h}$ followed by Western blotting analysis to examine mTOR activation. The data showed that phospho-mTOR was suppressed in a dose-dependent manner when Huh-7 cells were treated with traditional curcumin (Figure 2D-left panel). To examine the phospho-mTOR suppression by TML-6, we used traditional curcumin as a control at concentrations of 10 and $20 \mu \mathrm{g} / \mathrm{mL}$. Our data showed that phospho-mTOR was suppressed in all the concentrations of TML-6-treated Huh 7 cells. We also found that the average of phospho-mTOR reduced by about 30\% when the dose of TML- 6 was below IC50 (between 0.65 3.93 $\mu \mathrm{g} / \mathrm{mL}$ ) after treating with TML-6 (Figure 2D-right panel). Results from quantification also indicated that TML-6 reduced the same level of phospho-mTOR at a concentration of $5.24 \mu \mathrm{g} / \mathrm{mL}$, as compared to curcumin at $20 \mu \mathrm{g} / \mathrm{mL}$, with about 4 -fold potency of activities. These results indicate that the inhibition of phospho-mTOR by TML-6 is more effective than traditional curcumin (Figure 2D).

\subsubsection{TML-6 Suppresses A $\beta$ Production in N2a/APPswe Stable Cells}

Previous studies have demonstrated that curcumin can inhibit $\mathrm{A} \beta$ oligomerization and decreases amyloid [40]. In this study, the mouse neuroblastoma cell line N2a which harbors stable overexpression of APP with wild-type (WT) was used, and Swedish mutations were designed as N2a/APP and N2a/APPswe stable cell lines, respectively. The protein expression of APP was confirmed by Western blotting. Since the full-length WT APP plasmid has kicked out in N2a/APP stable cells, we used N2a/APPswe stable cell line for further study (Figure 3A). To examine whether the A $\beta$ production was affected by TML-6, the cell line N2a/APPswe was treated with traditional curcumin and TML- 6 for $24 \mathrm{~h}$ and kept the supernatant for ELISA analysis. The production of $A \beta$ levels was examined in culture medium by using $A \beta 40$ and $A \beta 42$ ELISA kit. Our data showed that TML- 6 reduced the production of $\mathrm{A} \beta 40$ and $\mathrm{A} \beta 42$ between 1.05, 2.09 and $3.14 \mu \mathrm{g} / \mathrm{mL}$ (equal to 2, 4 and $6 \mu \mathrm{M}$ ) in a dose-dependent manner. The least levels of $A \beta 40$ and $A \beta 42$ were reduced to approximately $86 \%$ and $80 \%$ at a concentration of $3.14 \mu \mathrm{g} / \mathrm{mL}$ of TML- 6 as compared with the control group (Figure $3 \mathrm{C}$ ). However, the levels of A $\beta 40$ and $A \beta 42$ after treating with traditional curcumin unexpectedly increased to levels higher than those of the control (CTRL) throughout the treatment at different doses, even cytotoxicity at the highest concentration of $20 \mu \mathrm{g} / \mathrm{mL}$ was demonstrated (Figure 3B). This phenomenon was also observed for 
low-dose $(1.05 \mu \mathrm{g} / \mathrm{mL})$ TML-6 treatment; however, the $\mathrm{A} \beta 40$ and $\mathrm{A} \beta 42$ levels started to decrease at a TML- 6 dose of $2.09 \mu \mathrm{g} / \mathrm{mL}$. This finding was supported by a previous observation that low-dose of curcumin can stimulate cell proliferation and potentially lead to increasing $A \beta$ production in the N2A/APPswe stable cell line [41,42]. Therefore, our data indicate that TML-6 can significantly suppress the production of $A \beta 40$ and $A \beta 42$ in N2a/APPswe cells.
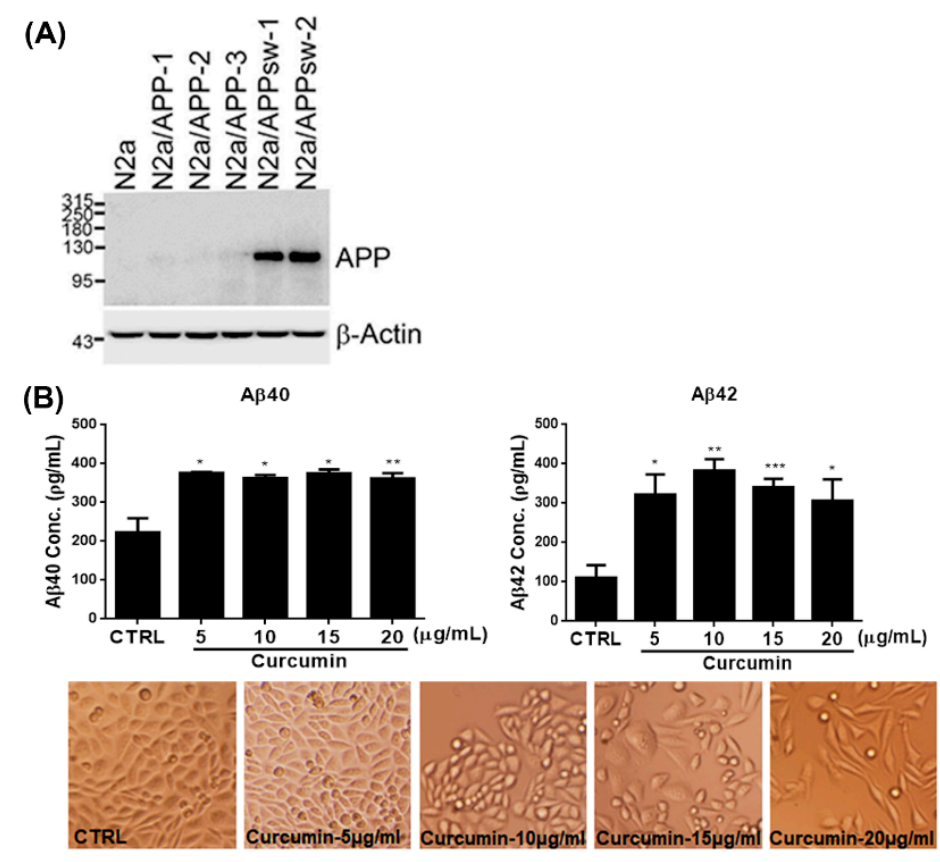

(C)
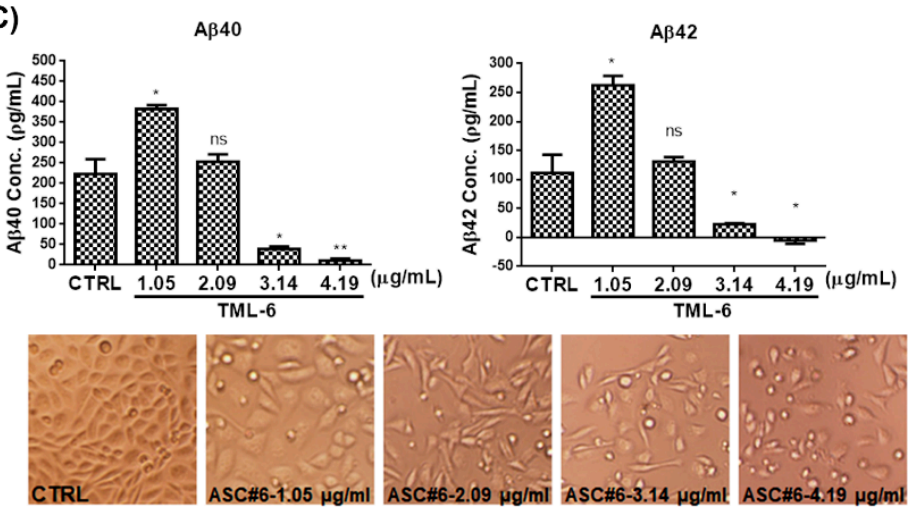

Figure 3. TML-6 suppresses A $\beta$ production in the N2a/APPswe stable cell line. (A) The N2a cell line showed stable over-expression of APP with wild-type full-length (N2a/APP) and Swedish mutant (N2a/APPswe) cells by Western blotting. The N2a/APPswe stable cell line was used to examine A $\beta$ 40 and $A \beta 42$ levels in culture medium in response to traditional curcumin and TML- 6 by ELISA test. N2a/APPswe stable cells were treated with different doses of traditional curcumin (B) and TML-6 (C) as indicated in the figures. The cell morphological change or viability in each treatment was captured and represented for comparison at the lower panel, as indicated. After $24 \mathrm{~h}$ incubation, the culture medium was examined for levels of $A \beta 40$ and $A \beta 42$ by LEGEND MAX ${ }^{\mathrm{TM}} \beta$-Amyloid X-40 and X-42 ELISA Kit. The significant differences between the treated and control cells are represented as the mean with a standard deviation (SD) error bar, and $p$ value $<0.05$ was considered significant ${ }^{*} p<0.05$, $\left.{ }^{* *} p<0.01,{ }^{* * *} p<0.001\right)$. The cell density, viability, and morphological changes by micrographs were similar between curcumin and TML-6, probably due to cytotoxicity at the highest doses of curcumin $(20 \mu \mathrm{g} / \mathrm{mL})$ and TML-6 $(4.19 \mu \mathrm{g} / \mathrm{mL})$ in N2a/APPswe stable cells. 
2.3. TML-6 Improved the Learning Behaviors, Significantly Suppressed the A $\beta$ Levels and Iba-1 Expression in the Brain of 3xTg AD Transgenic Mice

To verify the efficacy of TML- 6 as a potential therapeutic for AD, we conducted the animal study by using six-month-old 3xTg (mutations: $\mathrm{APP}_{\mathrm{KM} 670 / 671 \mathrm{NL}}, \mathrm{MAPT}_{\mathrm{P} 301 \mathrm{~L}}$ and PSEN1 ${ }_{\mathrm{M} 146 \mathrm{~V}}$ ) AD transgenic mice fed with normal diets (vehicle), diets mixed with traditional curcumin, or diet containing TML-6 $(150 \mathrm{mg} / \mathrm{kg} / \mathrm{day})$ for four months. After 4 months, the 3xTg AD mice were examined for learning and memory behavior by the Morris water maze test. The brain tissues were verified for the expression of $A \beta$ levels and the microglial activation marker, Iba-1, by immunofluorescence staining.

In the Morris water maze test that was performed to examine spatial cognition, the AD transgenic mice fed with traditional curcumin had no significant difference as compared with the vehicle control (Figure 4A). However, latency to the submerged platform and time spent significantly decreased at the end of the six sessions in the group fed with TML-6 (Figure 4A). Our behavior data therefore showed that the 3xTg AD transgenic mice fed with TML-6 showed significantly improved hippocampus-dependent learning behavior as compared with traditional curcumin $(p=0.0094)$ and the vehicle control $(p=0.0399$, Figure 4A).

Following the behavior test, the animals were sacrificed and the mouse brain sections were examined by immunofluorescence staining for $A \beta$ and Iba- 1 . The expression levels of $A \beta$ in the brain of $3 x \operatorname{Tg}$ AD transgenic mice fed with different chow diets are represented in Figure $4 \mathrm{~b}$. The data showed that the expression of $\mathrm{A} \beta$ was significantly reduced by $51 \%(p=0.0035)$ in $3 \times \mathrm{Tg}$ AD mice fed with TML-6 as compared with the vehicle control (Figure 4B). However, 3xTg AD mice fed with traditional curcumin showed a trend of reduction but without significant differences $(p=0.1343)$, compared with the vehicle group (Figure 4B).

Brain inflammation is an important risk associated with AD progression. To investigate whether brain inflammation was also suppressed by TML-6, we examined the expression of Iba-1, a biomarker of microglial activation, in the groups of mice fed with vehicle, traditional curcumin, and TML-6. The data revealed that TML- 6 significantly suppressed the expression of Iba- 1 by $50 \%(p=0.0473)$ in $3 \times \mathrm{Tg}$ AD mice in the brain region of hippocampus as compared with the vehicle control (Figure 4C). However, $3 x \operatorname{Tg}$ AD mice fed with traditional curcumin had no significant change of Iba-1 expression levels as compared with the vehicle control $(p=0.6262)$ (Figure 4C).

In summary, TML-6 significantly improves the learning behavior of 3xTg AD transgenic mice. The expression of $A \beta$ and Iba- 1 levels in 3xTg AD transgenic mouse brains were reduced, which implies that hippocampus-dependent learning behavior was probably restored through the suppression of amyloid accumulation and brain inflammation by TML-6. 
(A) 3xTg AD transgenic mice

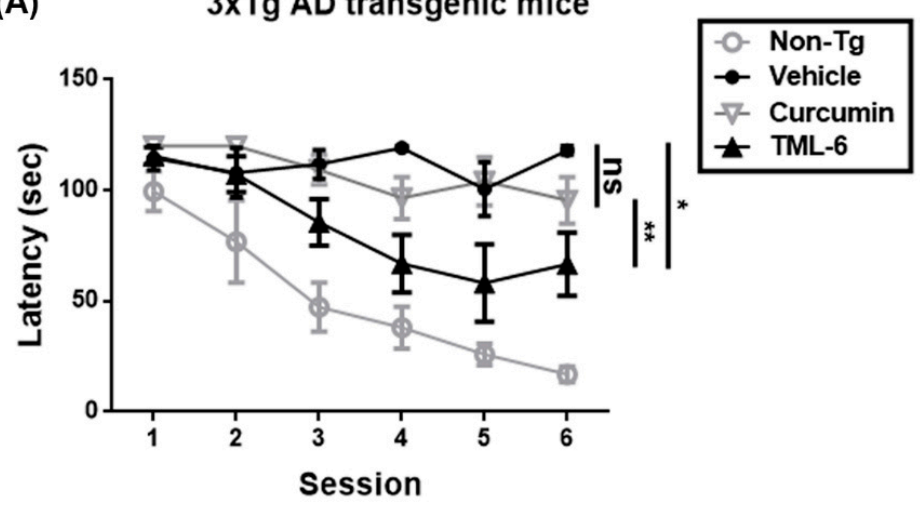

(B)
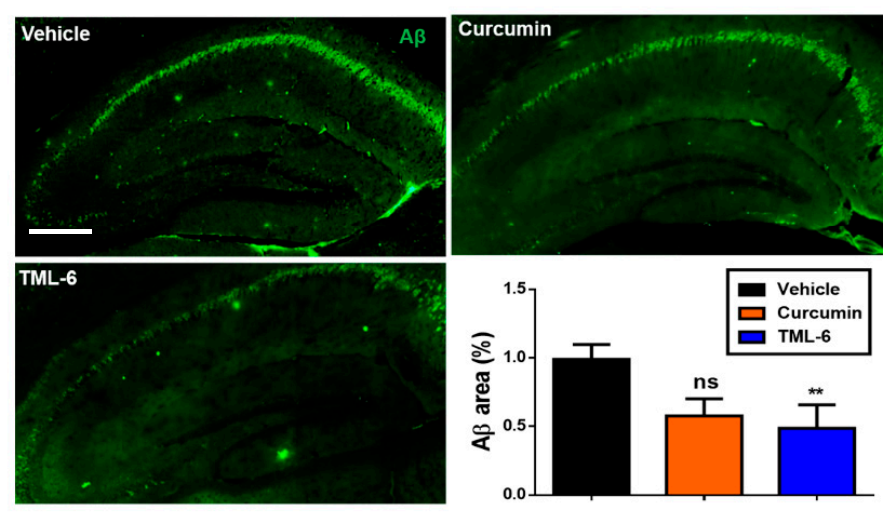

(C)
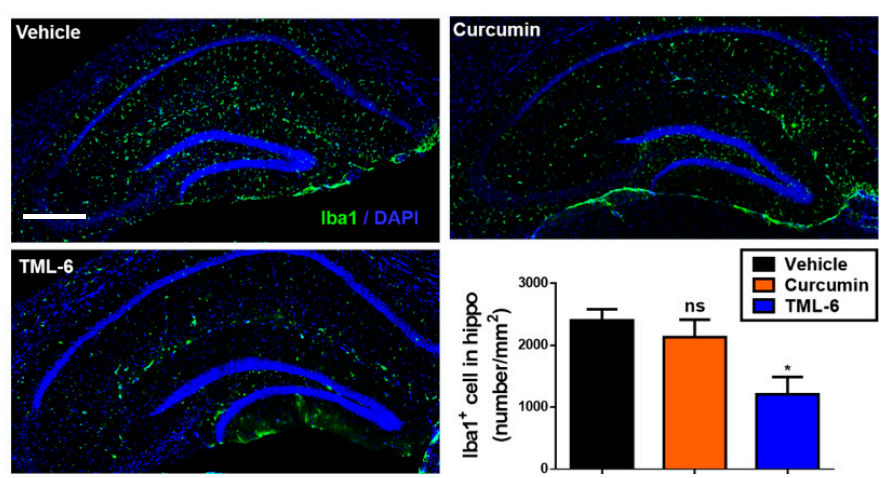

Figure 4. TML-6 improved the behavior test and reduced the brain levels of $A \beta$ and the inflammatory biomarker Iba1 in the 3x-Tg AD mouse model. (A) Six-month old 3x-Tg AD mice were fed with normal diets (vehicle), or diets containing traditional curcumin and TML-6 for four months at a dosage of $150 \mathrm{mg} / \mathrm{kg}$ (each group contained five mice, $n=5$ ). After four months of treatment on the experimental diet, animals were subjected to a behavior test in the form of the Morris water maze. The figure shows data from vehicle, curcumin and TML-6 fed different chow diets, with triplex-Tg AD mice and non-transgenic mice (Non-Tg) serving as the control. (B) The A $\beta$ levels in mouse brains in $3 x-T g A D$ mice were examined at the end of behavior test after four-month feeding with the treatment of normal diets, traditional curcumin and TML-6. Mouse brain sections were examined by immunofluorescence staining. The immunofluorescence staining of $A \beta$ was quantified and is represented in the panel. Scale bar: $200 \mu \mathrm{m}$. (C) Mouse brain sections were also examined for the inflammatory biomarker Iba1 by immunofluorescence staining. The images of Iba- 1 levels were represented and quantified as indicated in the panel. The significance of the behavior test, $A \beta$, and Iba- 1 levels between the mice treated with normal diets (vehicle) and either curcumin or TML- 6 was determined by paired $t$-test. Asterisks denote data representing the mean with a standard deviation (SD) error bar, and $p$ value $<0.05$ was considered significant $\left({ }^{*} p<0.05\right.$ and $\left.{ }^{* *} p<0.01\right)$. 


\subsection{Pharmacokinetic Studies}

According to previous reports, curcumin is difficult to be developed as a drug due to the poor bioavailability. Thus, the bioavailability of TML-6 is critical to be developed as a drug against AD. The pharmacokinetic (pK) study of curcumin and TML-6 was performed in blood after oral administration of $150 \mathrm{mg} / \mathrm{kg}$ in SD rats. The $\mathrm{pK}$ studies showed that the concentrations of curcumin at each time point were not detectable in rat blood, which is consistent with the poor bioavailability previously reported for curcumin (Figure 5A). However, the blood levels of TML-6 in plasma reached the peak levels of C-max of $35.9 \pm 15.6 \mathrm{ng} / \mathrm{mL}$ and T-max of $3.67 \pm 2.08 \mathrm{~h}$ (Figure $5 \mathrm{~A}, \mathrm{~B}$ ). This result indicates that the bioavailability of TML-6 shows a significant improvement as compared to traditional curcumin in SD rats after oral administration of $150 \mathrm{mg} / \mathrm{kg}$ curcumin and TML-6.

\begin{tabular}{|c|c|c|c|c|c|c|c|c|}
\hline Administration & No. of rats & $\begin{array}{c}\text { Oral Dose } \\
(\mathrm{mg} / \mathrm{Kg})\end{array}$ & $\begin{array}{c}\mathrm{C}_{\max } \\
(\mathrm{ng} / \mathrm{mL})\end{array}$ & $\begin{array}{l}\mathrm{T}_{\max } \\
(\mathrm{hr})\end{array}$ & $\begin{array}{l}\mathrm{AUC}_{(0-\mathrm{last})} \\
\left(\mathrm{ng}{ }^{*} \mathrm{hr} / \mathrm{mL}\right)\end{array}$ & $\begin{array}{c}\mathrm{AUC}_{(0-8)} \\
\left(\mathrm{ng} \mathrm{hr}^{\mathrm{hr}} / \mathrm{mL}\right)\end{array}$ & $\begin{array}{c}\text { MRT } \\
(\mathrm{hr})\end{array}$ & $\begin{array}{l}\mathrm{t}_{1 / 2} \\
(\mathrm{hr})\end{array}$ \\
\hline \multirow{2}{*}{ Curcumin } & Curcumin & \multirow{2}{*}{150} & \multirow{2}{*}{ ND } & \multirow{2}{*}{$\mathrm{ND}$} & \multirow{2}{*}{ ND } & \multirow{2}{*}{ ND } & \multirow{2}{*}{$\mathrm{ND}$} & \multirow{2}{*}{$\mathrm{ND}$} \\
\hline & $(\mathrm{N}=3)$ & & & & & & & \\
\hline \multirow{2}{*}{ TML-6 } & TML-6 & \multirow{2}{*}{150} & \multirow{2}{*}{$\begin{array}{c}35.9 \\
\pm 15.6\end{array}$} & \multirow{2}{*}{$\begin{array}{c}3.67 \\
\pm 2.08\end{array}$} & \multirow{2}{*}{$\begin{array}{c}177 \\
\pm 76.8\end{array}$} & \multirow{2}{*}{$\begin{array}{c}181 \\
\pm 78.7\end{array}$} & \multirow{2}{*}{$\begin{array}{c}3.91 \\
\pm 0.62\end{array}$} & \multirow{2}{*}{$\begin{array}{c}1.27 \\
\pm 0.51\end{array}$} \\
\hline & $(\mathrm{N}=3)$ & & & & & & & \\
\hline
\end{tabular}

(B)

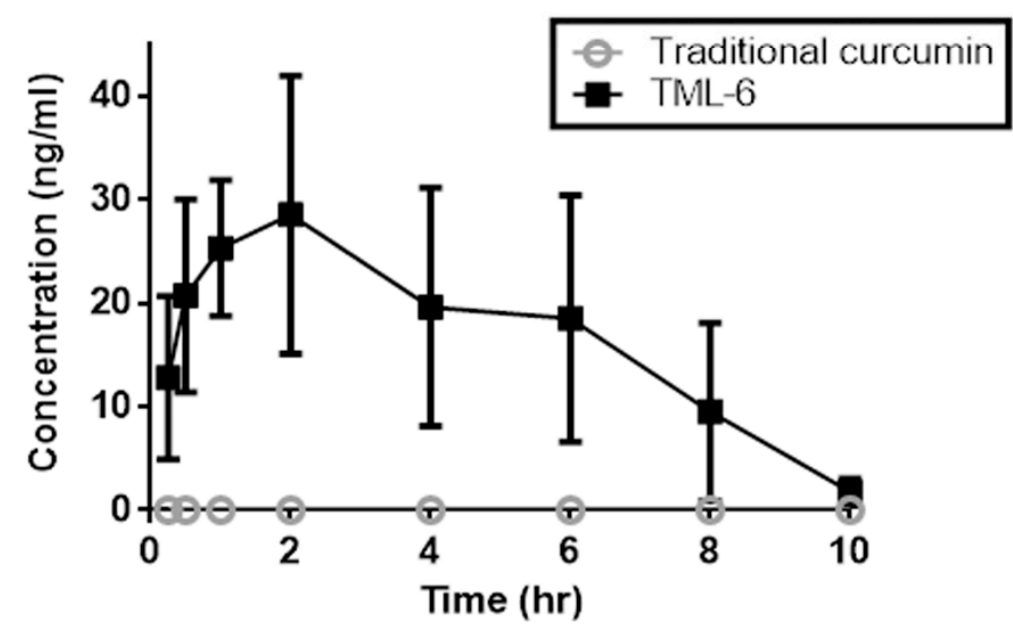

Figure 5. TML-6 exhibited significantly improved bioavailability as compared to traditional curcumin. (A) Summary of the absorption data on traditional curcumin and TML-6 in male Sprague-Dawley rats after oral administration of curcumin and TML- 6 of $150 \mathrm{mg} / \mathrm{kg}$. Values represented the mean \pm SD of three rats in each treatment group. Abbreviations: ND, not detectable. (B) Bioavailability (serum concentration) of traditional curcumin and TML- 6 was plotted against the time after oral administration to rats. The $\mathrm{pK}$ of curcumin was almost non-detectable (ND), consistent with the previous reports. Cmax indicates the observed maximum blood concentration and the time to reach the maximum blood concentration, while Tmax was determined directly from the experimental values. AUC (0-last) indicates the area under the concentration-time curve from time 0 to the last measurable concentration and MRT indicates the mean residence time.

\section{Discussion}

In this study, we reported for the first time that the novel curcumin analog TML-6 may represent a drug candidate for $\mathrm{AD}$ therapy, meeting the current strategy to develop AD drugs targeting at multiple 
pathways in AD pathogenesis. TML-6 exhibited multiple biological effects on combining aging biology and AD pathogenesis, including the inhibition of APP and A $\beta$ synthesis, the upregulation of ApoE, the transcriptional activation of the anti-oxidative Nrf2 gene, the suppression of phospho-mTOR, and the inhibition of proinflammatory phospho-NF- $\mathrm{kB}$. Importantly, the $3 \mathrm{x}-\mathrm{Tg}$ AD mouse studies revealed improvements in learning behavior, reduced accumulation of $A \beta$ levels, and suppression of the microglia activation marker Iba- 1 in the brain. Although similar to the biologic effects of traditional curcumin, TML-6 exhibited significantly potent biological activities of up to 5-10-fold at each dose concentration as compared to curcumin. Furthermore, TML-6 showed considerably improved pharmacokinetic levels in the plasma as compared to the almost undetectable levels for traditional curcumin.

The potential of curcumin for clinical therapy has been a long-term huge controversy [43]. This controversy results from its pan assay interference compound (PAIN) [33,34] and poor bioavailability [44]. Both issues are the major medical concerns to be solved by chemical interaction studies, the formulation optimization, and clinical trial in the future drug development. In the past decades, hundreds to thousands of publications have reported on the in vitro and in vivo biological effects of curcumin in anti-aging and human diseases [36,45]. In order to mitigate this drawback of curcumin in drug development, many efforts have been made in the past decades to develop a bioavailable curcumin through drug delivery and formulation [44]. Recently, a few clinical studies using formulated curcumin have revealed significantly improved bioavailability and efficacy in human disease studies [46]. The most notable progress is the recent randomized, placebo-controlled trial report from UCLA which used a bioavailable form of curcumin for the therapy of non-demented AD adults. The results showed improved memory and reduced accumulation of $A \beta /$ tau in the brain region by using 2-(1-\{6-[(2-[F-18]fluoroethyl)(methyl) amino]-2-naphthyl\} ethylidene)malononitrile (FDDNP) microimaging positron emission tomography (PET) after treating for 18 months [36,47]. This UCLA report offers the first proof of concept in therapeutic potential of formulated curcumin and its analog for AD therapy.

In agreement with previous reports, we demonstrated that curcumin and TML- 6 can suppress the synthesis of APP [48]. Curcumin significantly decreased both $A \beta 40$ and $A \beta 42$ levels in rat neuroblastoma B104-APP751 and human neuroglioma H4-APP751 stable cell lines at 15 and $20 \mu \mathrm{M}$ with no cytotoxicity. The inhibition of APP by curcumin was previously reported to mediate through the inhibition of the maturation process of the APP molecule. An interesting finding in this study is the remarkable inhibition of $A \beta 40$ and $A \beta 42$ synthesis by TML- 6 , but not by curcumin. Despite the cytotoxicity of the N2a/APPsw cell line found in the highest concentration of curcumin and TML-6, the $A \beta 40$ and $A \beta 42$ levels were significantly inhibited by TML- 6 at $3.14 \mu \mathrm{g} / \mathrm{mL}$, implying that the secretion of $A \beta$ was reduced in the APP Swedish mutation-overexpressed N2a cell line (N2a/APPsw). This in vitro data were further verified in the AD transgenic mouse model, which showed significant reduction in $A \beta$ in the mouse brain regions after feeding with TML-6. The current theory of AD pathogenesis is principally based on the study of early-onset AD patients, which showed alteration of mutant genes, such as APP, tau and presenilin $[4,49]$. Although the pathway involving APP/A $\beta /$ tau represents the dominant mechanism of $\mathrm{AD}$ pathogenesis, the failure of many drug development efforts at the late stage trial raises the possibility that other non-amyloid AD mechanisms or alternative pathways should be explored in the development of therapeutics for $\mathrm{AD}$ [2]. In this scenario, our molecule TML-6, which exhibited multifaceted biological effects by combining the A $\beta$ cascade and aging-related pathways, should shed light on the development of novel therapeutics for AD.

One new finding in this study is the demonstration of the upregulation of ApoE by curcumin and TML- 6 for the first time. Apo E plays an important role in the lipid metabolism and the catabolism of $\mathrm{A} \beta$ clearance, which is closely related to AD pathogenesis [13]. Although several pathways associated with ApoE-related AD have been reported, the mechanism of ApoE in AD pathogenesis is not well elucidated. Cramer and colleagues reported that treatment with the retinoid $X$ receptor (RXR) agonist bexarotene in $\mathrm{AD}$ transgenic mice resulted in the reversal of $\mathrm{AD}$ deficit, which is ApoE-dependent [13]. 
Preliminary studies in our laboratory revealed that curcumin and TML-6 upregulated ApoE expression through the PPAR $\alpha / R X R \alpha$ responsive elements in the ApoE promoter region. The ApoE levels in cerebrospinal fluid and plasma tend to be lower in patients with AD than in healthy individuals, as observed in cohort and meta-analysis studies $[15,16]$. Therefore, increasing the expression of Apo E in all $A P O E$ genotypes may provide a therapeutic strategy against AD.

One provocative theory in $\mathrm{AD}$ pathogenesis is the role of mTOR and the autophagy machinery mechanism. Recently, Lambeth and colleagues reported that long-lived protein can spontaneously modify substrates and gradually disrupt the lysosomal protein degradation pathway [50]. Therefore, activation of the cellular autophagy lysosomal system regulated by mTOR may provide one alternate strategy for aggregated protein clearance. In this study, both curcumin and TML-6 can cause downregulation of the mTOR pathway through suppression of phospho-mTOR for about $50 \%$ as compared to the control. mTOR is a key regulator of lifespan and affects aging-related pathogenesis such as mRNA translation, regulation of autophagosome, and metabolism [51,52]. A recent study showed that mTOR activation can enhance $A \beta$ production by upregulating $\beta$ - and $\gamma$-secretase cleavage [53]. Furthermore, the activation of mTOR may downregulate $A \beta$ clearance through the dysfunction of autophagy machinery, which may subsequently result in the accumulation of $A \beta$ deposition and formation $[54,55]$. Therefore, the inhibition of mTOR by TML- 6 may activate autophagy machinery, not only providing a therapeutic strategy for $\mathrm{AD}$, but also ameliorating the aging process.

The most notable recent theory of AD pathogenesis is the unifying concept of the aging process as the driving role in neurodegenerative diseases and AD [56]. The emergence of free radicals has been reported to play a major role in the aging-related process [21]. Reactive oxygen species (ROS) are one kind of free radicals which may attack proteins, lipids, and DNA, leading to the activation of a series of mutagenesis processes in the aging process [57]. TML-6 could transcriptionally activate the $N r f 2$ gene in a dose-dependent manner, with the highest activity at a concentration of $1.32 \mu \mathrm{g} / \mathrm{mL}$. Currently, antioxidant and anti-inflammatory effects of the ketogenic diet can provide neuroprotection in AD through effective cognitive processes and support the concept of life style change in anti-aging and ameliorating AD progression [58]. The strong anti-oxidative effect of curcumin or TML-6 may initiate the downstream signal of aging or AD pathogenesis. Whether curcumin or TML-6 exhibits multiple biologic targets or, alternatively, they only exert an initiating anti-oxidative role of aging which then drives the subsequent aging biology, requires further clarification. These implications also indicate that the inhibition of upstream anti-oxidative ROS may explain the effects of TML-6 on the multiple downstream effects of TML-6, as shown in Figure 6. This possibility indicates the importance of the antioxidant effect on aging biology and $\mathrm{AD}$, moving beyond the traditional amyloid and tau approaches.

Finally, a few challenges exist for future drug development of TML-6. One concern is the potential toxicity of TML- 6 based on the IC50 of TML-6 in Huh-7, although our preliminary data on toxicological experiments showed no obvious toxicity in the rat model. The other challenges of TML- 6 in preclinical studies will be to optimize the formulation development to improve the solubility and absorption of the unformulated TML- 6 that was used in the cell biology and AD transgenic mouse model in this study. Preliminary data also showed a low brain penetration of $3 \mathrm{ng} / \mathrm{mL}$ ( $10 \%$ of the plasma $\mathrm{pK}$ levels) in AD mice receiving $150 \mathrm{mg} / \mathrm{kg}$ of TML-6, while it was not detected in the brain of the normal mice receiving the same dose of it. These findings are unexpected but interesting considering the recent report on the dysfunction of $\mathrm{BBB}$ in the AD brain. In AD individuals, the deposit of $\mathrm{A} \beta$ in the vascular endothelium may result in angiopathy, thus, drugs or blood substance may gain access to neural tissues [59]. This possibility may explain the efficacy of TML-6 in improving the behavior and the reduction in $\mathrm{A} \beta$ in brain tissues that were observed in our $\mathrm{AD}$ transgenic mouse model. 


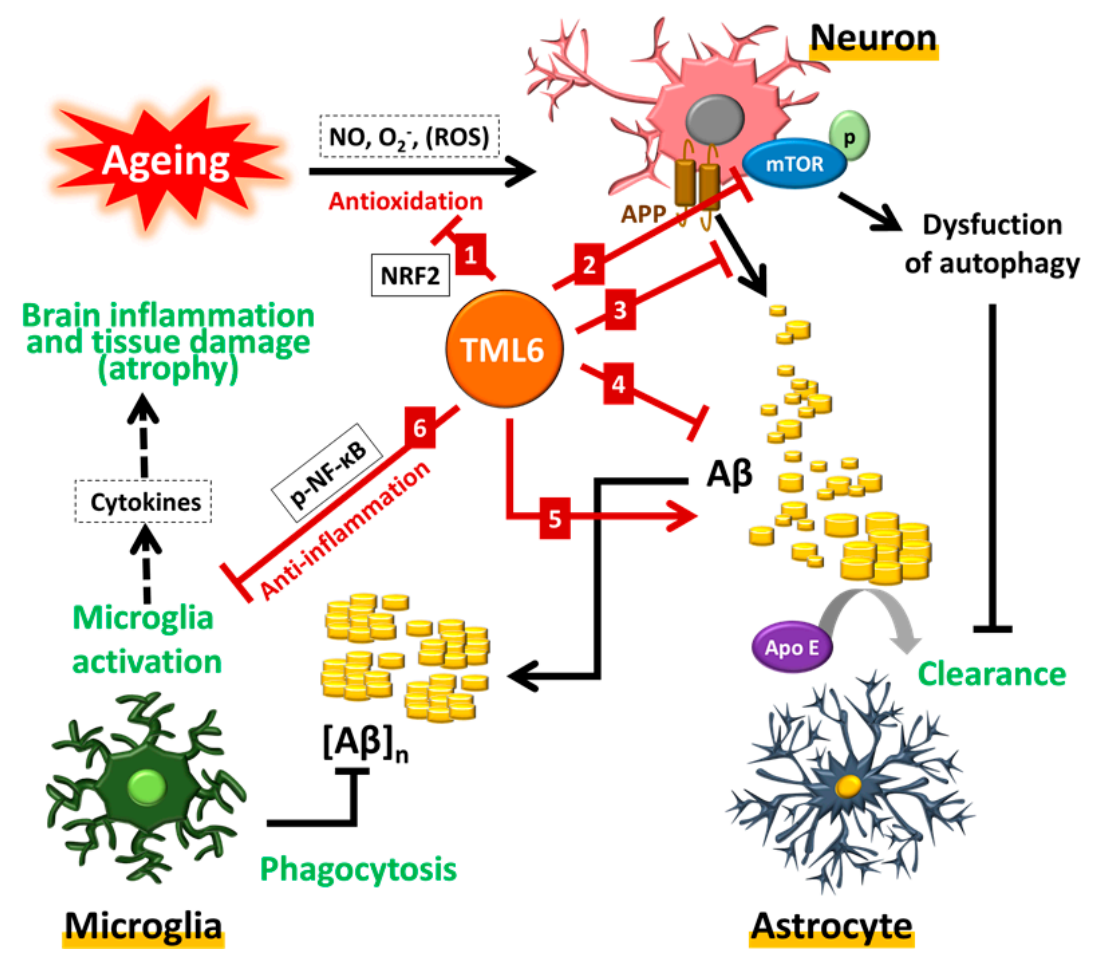

Figure 6. A hypothetical scheme on the potential action mechanism of TML-6 in the therapy of Alzheimer's disease. Curcumin derivative-TML-6 treatments can induce (1) transcriptional activation of the Nrf2 promoter, which can reduce free radicals, the hallmark of the aging process; (2) following the aging process, the dysfunction of autophagy machinery and activation of mTOR will reduce the autophagolysosomal function to remove the misfolded proteins and lead to the accumulation of A $\beta$. TML- 6 can effectively inhibit the phosphorylation of mTOR and maintain the normal function of autophagy to assure A $\beta$ clearance; (3) TML6 can inhibit the production of A $\beta$ from APP and (4) suppress the synthesis and secretion of A $\beta$ from neurons; (5) TML6 can transcriptionally activate APOE and enhance the clearance of A $\beta$; (6) TML6 can inhibit the activation of microglial cells and reduce inflammatory injuries in the brain. The future design of therapeutics should combine targeting $\mathrm{APP} /$ the $\mathrm{A} \beta$ cascade and improving aging-related biological processes.

\section{Materials and Methods}

\subsection{The Curcumin Analog TML-6}

A panel of 12 synthetic curcumin analogs were obtained from the AndroScience Company (ASC, San Diego, CA, USA), the products of which were later acquired by the Allianz Biotechnology Company, Taipei, Taiwan. Due to the historical belief on the role of curcumin in anti-aging and AD prevention, Professor Ih-Jen Su of the Southern Taiwan University of Science and Technology started to screen these compounds by adopting 6 molecular markers related to aging and $\mathrm{AD}$ pathogenesis to identify a drug candidate for AD. The compound ASC-6, later re-named as TML-6, was finally selected as the candidate compound based on the data of cytotoxicity, biologic activities, and pharmacokinetics. The triplex-Tg AD mice were then conducted to evaluate the efficacy.

The active pharmaceutical ingredients of TML- 6 were synthesized and physico-chemical properties were characterized by SinoPharm Pharmaceutical Company (SPT), Tainan, Taiwan. Preformulation studies on the solubility of TML-6 were conducted by Value Pharmaceutical Services (VPS) Company, Jiansu, China. All the data in this study were conducted using unformulated TML-6. Formulation to optimize the solubility and permeability of TML-6 is under development for toxicological studies. 


\subsection{Cell Lines, Cell Culture, and Chemicals}

A total of 5 cell lines (Huh-7, HepG2, SH-SY5Y, U373MG, and N2a) were examined for the feasibility of expression of aging and AD-related proteins. Among them, two cell lines were chosen for the working model for screening curcumin derivatives based on the dose-dependent expression of APP and ApoE. The human hepatoma Huh-7 cell lines were obtained from the Health Science Research Resources Bank (JCRB0403; Osaka, Japan) and the mouse neuroblastoma cell line N2a cells with stable overexpression of full-length APP and APP Swedish mutations, designated as N2a/APPswe, were kindly provided by Prof. Kuo, Yu-Min, National Cheng Kung University Medical School, Tainan, Taiwan. For cell biology studies, TML-6 was dissolved in DMSO to obtain stock solution. Both cell lines were then cultured in Dulbecco's modified Eagle's medium (DMEM, Gibco, Grand Island, NY, USA) supplemented with $100 \mathrm{U} / \mathrm{mL}$ penicillin, $100 \mathrm{mg} / \mathrm{mL}$ streptomycin and $10 \%$ fetal bovine serum (FBS, Biological Industries, Cromwell, CT, USA). Cells were cultured at $37^{\circ} \mathrm{C}$ in a humidified atmosphere of a $5 \% \mathrm{CO}_{2}$ incubator (Forma Scientific, Marietta, $\mathrm{OH}, \mathrm{USA}$ ). The cells were seeded in 24-well plates, or 6- or 10- $\mathrm{cm}$ dishes overnight on the day before the experiment. On the next day, the cells were treated with traditional curcumin (Sigma, St. Louis, MO, USA) and TML-6. The working concentration of each compound is indicated in the figures.

\subsection{Cytotoxicity Assay}

The cytotoxicity assay was performed using the Cell Counting Kit-8 (CCK-8, Sigma). We dissolved $0.0524 \mathrm{~g}$ of TML-6 (molecular weight is $523.62 \mathrm{~g} / \mathrm{mol}$ ) in $10 \mathrm{~mL}$ DMSO to obtain TML-6 stock at $10 \mathrm{mM}$ for cell line study. The working concentrations at $0.3125,0.625,1.25,2.5,5,10$ and $20 \mu \mathrm{M}$ were diluted from $10 \mathrm{mM}$ TML-6 stock in culture medium. For data presentation in cytotoxicity assay, we converted the working concentration of $\mu \mathrm{M}$ into $\mu \mathrm{g} / \mathrm{mL}$ as indicated in Figure 2A. Briefly, Huh-7 cells were seeded overnight in 96-well plates at 5000 cells/well and then subjected to traditional curcumin or TML-6 treatment for $24 \mathrm{~h}$. At each time point, a CCK-8 solution $(0.25 \mathrm{mg} / \mathrm{mL})$ was added to the medium in each well for an additional $4 \mathrm{~h}$ incubation, and absorbance was measured at $570 \mathrm{~nm}$ using an ELISA reader.

\subsection{Cell Lysis and Western Blotting}

After cells were seeded and treated with curcumin and TML- 6 for $24 \mathrm{~h}$, cells were washed with ice-cold PBS (Phosphate Buffered Saline) and lysed with $100 \mu \mathrm{L}$ of RIPA cell lysis buffer (Pierce Biotechnology, Rockford, IL, USA) supplemented with protease and phosphatase inhibitors (Roche Diagnostics, Mannheim, Germany). Cell lysates were further cleaned by centrifugation at 14,000 rpm at $4{ }^{\circ} \mathrm{C}$ for $15 \mathrm{~min}$. Protein concentration was determined using a Bradford assay (Bio-Rad, Hercules, CA, USA). For Western blot analysis, $20 \mu \mathrm{g}$ of each sample was prepared for SDS-PAGE (SDS Poly-acrylamide-gel-electrophoresis) and denatured at $95^{\circ} \mathrm{C}$ for $10 \mathrm{~min}$. The samples prepared from total lysates were loaded and separated by SDS-PAGE $(8 \%$ or $10 \%)$, and then transferred to PVDF membranes (pore size $0.45 \mu \mathrm{m}$; PerkinElmer, Waltham, MA, USA) by semi-dry transfer cell (Bio-Rad). After blocking with 5\% skim milk in PBS-T (0.1\% Tween-20), the membranes were hybridized with primary antibodies at $1 / 1000$ dilution at $4{ }^{\circ} \mathrm{C}$ overnight. On the next day, membranes were washed with PBS-T followed by incubation with HRP-conjugated anti-mouse or anti-rabbit secondary antibody (DAKO, Santa Clara, CA, USA) at 1/5000 dilution at room temperature for $1 \mathrm{~h}$ as appropriate. Finally, the images were captured by Amersham Imager 600 (GE Healthcare Life Sciences, Marlborough, MA, USA) after being developed using the chemiluminescent HRP substrate (Millipore, Bedford, MA, USA). The primary antibodies used in this study were anti-APP, anti-NF- $\kappa B$ (Cell Signaling Technology, Danvers, MA, USA), anti-Apo E, anti-p-mTOR (Abcam, Cambridge, MA, USA).

\subsection{Amyloid $\beta$ Enzyme-Linked Immunosorbent Assay}

Extracellular levels of soluble $\mathrm{A} \beta 40$ and $\mathrm{A} \beta 42$ were determined by LEGEND MAX ${ }^{\mathrm{TM}} \beta$-Amyloid $\mathrm{x}-40$ and X-42 ELISA Kit (Biolegend, San Diego, CA, USA). Overexpression of the APP Swedish mutation 
(APPswe) in the N2a neuronblastoma cell line was called the N2a/APPswe cell line. N2a/APPswe stable cells were seeded at $8 \times 10^{5}$ cells in $6 \mathrm{~cm}$ dishes. After overnight incubation, the cells were treated with curcumin and TML- 6 for $24 \mathrm{~h}$. The working concentrations of curcumin and TML-6, as indicated in Figure 2, were prepared by dissolving the TML-6 in DMSO as stock solution and then diluted in $3 \mathrm{~mL}$ DMEM medium. The culture supernatant was collected and centrifuged at $1500 \times \mathrm{g}$ at $4{ }^{\circ} \mathrm{C}$ for $5 \mathrm{~min}$ to remove cells. The culture supernatants from various treatments were conducted to examine the $A \beta$ levels according to the manufacturer's instructions. The samples for the detection of soluble $A \beta$ levels were diluted in the supernatant at a 1:10 dilution for this experiment. Levels of soluble $A \beta$ were detected by measuring the OD at $620 \mathrm{~nm}$ (Molecular Devices, San Jose, CA, USA). The calculation of $A \beta$ levels was based on the standard curves of $A \beta 40$ and $A \beta 42$, respectively.

\subsection{Luciferase Reporter Assay}

To examine the activities of the anti-oxidative gene NrF2, Huh-7 cells were seeded in 24-well culture plates and then co-transfected with serial dilution of pG5-Nrf2-Luc (firefly luciferase) with the pRL-TK Renilla luciferase reporter. Following overnight incubation, the transfected cells were treated with traditional curcumin and TML-6 compounds for additional $24 \mathrm{~h}$. The luciferase reporter assay was performed using the Dual-Luciferase Reporter assay system (Promega, Madison, WI, USA). The cell lysates were assayed for both firefly and Renilla luciferase activities. The relative luciferase units (RLU) were measured using a luminometer (GLOMAX Multi, Promega). Firefly luciferase activity was normalized for transfection efficiency using the Renilla luciferase activity in each lysate as the control. The RLUs are expressed as means plus standard deviation of three independent experiments.

\subsection{AD Transgenic Mice and Diets}

The triplex transgenic mouse model (3xTg-AD, APP Swedish, MAPT P301L, and PSEN1 M146V) was adopted as the AD model and bred at the laboratory animal center of National Cheng Kung University (NCKU), Tainan, Taiwan [60]. The mice were housed in a room maintained on a $12 \mathrm{~h}$ light-dark cycle and fed ad libitum. Six-month old 3xTg-AD mice were used for animal experiments. Experimental procedures for handling the mice were in accordance with the guidelines of the Institutional Animal Care and Use Committee (IACUC) of NCKU. These mice develop plaques and tangles pathology. $\mathrm{A} \beta$ deposition is progressive, and deposition appears as early as nine months for triplex-Tg mice. The AD transgenic mice were fed with the control diet (Laboratory Rodent Diet 5001, LabDiet, St. Louis, MO, USA), the control diet plus traditional curcumin $(150 \mathrm{mg} / \mathrm{kg})$, or the control diet plus TML-6 $(150 \mathrm{mg} / \mathrm{kg})$ for four months. Diets were stored at $4{ }^{\circ} \mathrm{C}$ and were added to mouse cage twice a week. The quantity of the diet consumed by the mice was determined daily. The concentration of curcumin and TML- 6 in the diet was determined to be around $1.20 \mathrm{mg} / \mathrm{g}$ of diet after assaying by HPLC by the Development Center for the Biotechnology (DCB), Taipei, Taiwan.

\subsection{Morris Water Maze Test}

For assessing spatial learning and memory, the Morris water maze was used as we described before [61,62]. Mice were trained to memorize the location of a hidden platform in a swimming pool (120 cm diameter, $50 \mathrm{~cm}$ depth). The platform was $1 \mathrm{~cm}$ below the water surface. There were four different cues in each quadrant. Mice were allowed to explore the maze for four trials per session and 6 sessions in total in 6 days. Each trail lasted for $120 \mathrm{~s}$ and the resting time was $30 \mathrm{~s}$. The time taken to reach the platform was recorded as escape latency.

\subsection{Immunofluorescence Staining}

Mice were anesthetized using pentobarbital $(60 \mathrm{mg} / \mathrm{kg}$, intravenous) and then transcardial perfusion was performed with $0.01 \mathrm{M}$ PBS ( $\mathrm{pH}$ 7.4). The brains were post-fixed in $4 \%$ PFA (paraformaldehyde) for 2 days and dehydrated with $30 \%$ sucrose at $4{ }^{\circ} \mathrm{C}$. The hydrated brain was embedded with optimal cutting temperature compound (OCT, Leica, Wetzlar, Germany) and 
quick-freeze was performed at $-30^{\circ} \mathrm{C}$. The blocks were sectioned into $16 \mu \mathrm{m}$-thick slices. Slices were stored at $-20^{\circ} \mathrm{C}$. Before immunofluorescence staining, the sections were soaked in cold PBS for $5 \mathrm{~min}$. Antigen retrieval was performed with $0.01 \mathrm{M}$ citric acid at $100{ }^{\circ} \mathrm{C}$ for $5 \mathrm{~min}$. The sections were then blocked with 5\% normal donkey serum (Millipore) containing 0.1\% Triton X-100 (Sigma) in PBS-T. Primary antibody Iba1 (Wako, Richmond, VA, USA, 1:400) and A $\beta$ (Covance, Princeton, NJ, USA, 1:100) were used at room temperature for $1 \mathrm{~h}$. Alexa Fluor 488-conjugated anti-Rabbit antibody (for Iba1, Invitrogen Life Technologies, Grand Island, NY, USA, 1:300) and Alexa Fluor 488-conjugated anti-mouse antibody (for $A \beta$, Invitrogen Life Technologies, 1:300) were used, respectively. Images were captured by the TissureFAXS microscopy system and positive signals were quantified by TissueQuest software module (TissueGnostic, Vienne, Austria).

\subsection{Pharmacokinetic Studies}

In order to evaluate the bioavailability of curcumin and its analog TML-6, pharmacokinetic studies were commissioned and conducted by the Development Center for Biotechnology (DCB, Taipei, Taiwan). The kinetics of curcumin and TML-6 in blood were collected at 0.25, 0.5, 1, 2, 4, 6,8 and $10 \mathrm{~h}$ after oral administration of curcumin and TML- 6 at the dose of $150 \mathrm{mg} / \mathrm{kg}$ in male Sprague-Dawley Rats.

\subsection{Statistical Analysis}

Significant differences between traditional curcumin and TML-6 in the Nrf2 promoter (assessed by the luciferase reporter assay), A $\beta$ production in the N2a/APPswe stable cell line, and expression levels of $\mathrm{A} \beta$ and Iba- 1 in transgenic AD mice were determined by paired $t$-test ${ }^{*} p<0.05,{ }^{* *} p<0.01$, ${ }_{* * *} p<0.001$. Data represent the mean with a standard deviation (SD) error bar.

\section{Conclusions}

Together with many other reports in the literature on AD pathogenesis, we propose a work model to unify the complex pathogenesis of AD into one scenario based on the aging biology as described in Figure 6. The increasing prevalence of sporadic $\mathrm{AD}$ in the elderly suggests that the early events of $\mathrm{AD}$ may start with the aging process in the fifth decade of age in at-risk individuals. With the evolution of the aging process, oxidative stress prevails, which is followed by the dysfunction of the autophagy machinery, manipulating the misfolded proteins in the neurons of the aged individuals. The reduction in ApoE may not only worsen the cholesterol metabolism but also exacerbate amyloid plaque formation, which will trigger microglial activation and inflammation, leading to neuronal loss and brain atrophy. In agreement with the current concept to treat early-stage or non-demented AD patients, the gold standard for future drug development for AD should not only reduce $A \beta$ accumulation but must also improve the pathobiology associated with the aging process. In this scenario, the curcumin analog TML-6 meets the current strategy to develop therapeutics for the prevention and therapy of AD.

Author Contributions: Conceptualization, I.-J.S. and K.-J.T.; data curation, H.-Y.C. and H.-C.W.; formal analysis, H.-Y.C. and H.-C.W.; funding acquisition, I.-J.S. and K.-J.T.; methodology, H.-Y.C.; project administration, I.-J.S.; resources, I.-J.S. and K.-J.T.; writing-original draft, I.-J.S. and H.-Y.C.; writing-review and editing, I.-J.S. and K.-J.T. All authors have read and agreed to the published version of the manuscript.

Funding: This study was supported by grants from Ministry of Science and Technology, Taiwan (MOST-106-3114-8218-001, MOST-106-2628-B-006-001-MY4) and National Cheng Kung University Hospital, Taiwan (NCKUH-10909027) .

Acknowledgments: We are grateful to Ya-Chun Hsiao for the services of image acquiring and analyzing from the FACS-like Tissue Cytometry in "Bioimaging Core Facility of the National Core Facility for Biopharmaceuticals, Ministry of Science and Technology, Taiwan".

Conflicts of Interest: The authors declare that they have no competing interests. 


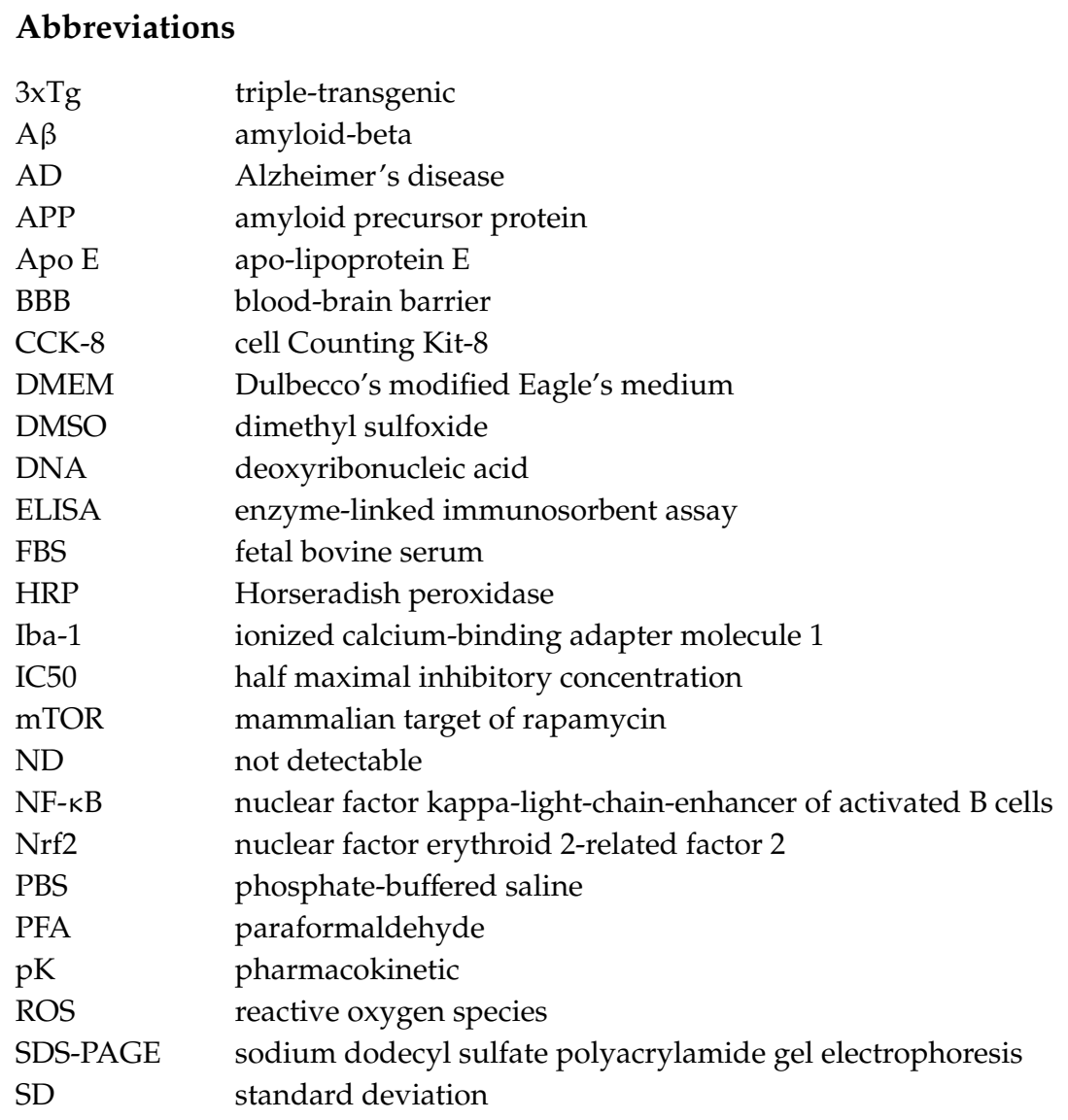

\section{References}

1. Alzheimer's Association. 2015 Alzheimer's disease facts and figures. Alzheimers Dement. 2015, 11, 332-384. [CrossRef] [PubMed]

2. Cummings, J.; Lee, G.; Ritter, A.; Zhong, K. Alzheimer's disease drug development pipeline: 2018. Alzheimers Dement. 2018, 4, 195-214. [CrossRef] [PubMed]

3. Cummings, J. Lessons Learned from Alzheimer Disease: Clinical Trials with Negative Outcomes. Clin. Transl. Sci. 2018, 11, 147-152. [CrossRef] [PubMed]

4. Kametani, F.; Hasegawa, M. Reconsideration of Amyloid Hypothesis and Tau Hypothesis in Alzheimer's Disease. Front. Neurosci. 2018, 12, 25. [CrossRef] [PubMed]

5. Lorenzo, A.; Yankner, B.A. Beta-amyloid neurotoxicity requires fibril formation and is inhibited by congo red. Proc. Natl. Acad. Sci. USA 1994, 91, 12243-12247. [CrossRef] [PubMed]

6. Oliveira, J.M.; Henriques, A.G.; Martins, F.; Rebelo, S.; da Cruz e Silva, O.A. Amyloid-beta Modulates Both AbetaPP and Tau Phosphorylation. J. Alzheimers Dis. 2015, 45, 495-507. [CrossRef]

7. Mariani, S.M. Amyloid, tau, and cell death in Alzheimer's disease. MedGenMed 2004, 6, 46.

8. Chow, V.W.; Mattson, M.P.; Wong, P.C.; Gleichmann, M. An overview of APP processing enzymes and products. Neuromol. Med. 2010, 12, 1-12. [CrossRef]

9. De Strooper, B. Lessons from a failed gamma-secretase Alzheimer trial. Cell 2014, 159, 721-726. [CrossRef]

10. Mehta, D.; Jackson, R.; Paul, G.; Shi, J.; Sabbagh, M. Why do trials for Alzheimer's disease drugs keep failing? A discontinued drug perspective for 2010-2015. Expert Opin. Investig. Drugs 2017, 26, 735-739. [CrossRef]

11. Van Dyck, C.H. Anti-Amyloid-beta Monoclonal Antibodies for Alzheimer's Disease: Pitfalls and Promise. Biol. Psychiatry 2018, 83, 311-319. [CrossRef] [PubMed]

12. NIH Summit Delivers Recommendations to Accelerate Therapy Development for Alzheimer's Disease. Available online: https://www.nih.gov/news-events/news-releases/nih-summit-delivers-recommendationsaccelerate-therapy-development-alzheimers-disease (accessed on 25 May 2018). 
13. Cramer, P.E.; Cirrito, J.R.; Wesson, D.W.; Lee, C.Y.; Karlo, J.C.; Zinn, A.E.; Casali, B.T.; Restivo, J.L.; Goebel, W.D.; James, M.J.; et al. ApoE-directed therapeutics rapidly clear beta-amyloid and reverse deficits in AD mouse models. Science 2012, 335, 1503-1506. [CrossRef] [PubMed]

14. Liu, C.C.; Liu, C.C.; Kanekiyo, T.; Xu, H.; Bu, G. Apolipoprotein E and Alzheimer disease: Risk, mechanisms and therapy. Nat. Rev. Neurol. 2013, 9, 106-118. [CrossRef]

15. Hesse, C.; Larsson, H.; Fredman, P.; Minthon, L.; Andreasen, N.; Davidsson, P.; Blennow, K. Measurement of apolipoprotein E (apoE) in cerebrospinal fluid. Neurochem. Res. 2000, 25, 511-517. [CrossRef] [PubMed]

16. Gupta, V.B.; Laws, S.M.; Villemagne, V.L.; Ames, D.; Bush, A.I.; Ellis, K.A.; Lui, J.K.; Masters, C.; Rowe, C.C.; Szoeke, C.; et al. Plasma apolipoprotein E and Alzheimer disease risk: The AIBL study of aging. Neurology 2011, 76, 1091-1098. [CrossRef] [PubMed]

17. Griffin, W.S.; Sheng, J.G.; Roberts, G.W.; Mrak, R.E. Interleukin-1 expression in different plaque types in Alzheimer's disease: Significance in plaque evolution. J. Neuropathol. Exp. Neurol. 1995, 54, $276-281$. [CrossRef]

18. Garwood, C.J.; Pooler, A.M.; Atherton, J.; Hanger, D.P.; Noble, W. Astrocytes are important mediators of Abeta-induced neurotoxicity and tau phosphorylation in primary culture. Cell Death Dis. 2011, 2, e167. [CrossRef]

19. McGeer, P.L.; McGeer, E.G. NSAIDs and Alzheimer disease: Epidemiological, animal model and clinical studies. Neurobiol. Aging 2007, 28, 639-647. [CrossRef]

20. Son, S.M.; Song, H.; Byun, J.; Park, K.S.; Jang, H.C.; Park, Y.J.; Mook-Jung, I. Altered APP processing in insulin-resistant conditions is mediated by autophagosome accumulation via the inhibition of mammalian target of rapamycin pathway. Diabetes 2012, 61, 3126-3138. [CrossRef]

21. Liguori, I.; Russo, G.; Curcio, F.; Bulli, G.; Aran, L.; Della-Morte, D.; Gargiulo, G.; Testa, G.; Cacciatore, F.; Bonaduce, D.; et al. Oxidative stress, aging, and diseases. Clin. Interv. Aging 2018, 13, 757-772. [CrossRef]

22. Ahmad, W.; Ijaz, B.; Shabbiri, K.; Ahmed, F.; Rehman, S. Oxidative toxicity in diabetes and Alzheimer's disease: Mechanisms behind ROS/ RNS generation. J. Biomed. Sci. 2017, 24, 76. [CrossRef] [PubMed]

23. Murphy, K.E.; Park, J.J. Can Co-Activation of Nrf2 and Neurotrophic Signaling Pathway Slow Alzheimer's Disease? Int. J. Mol. Sci. 2017, 18, 1168. [CrossRef] [PubMed]

24. Hosseinkhani, A.; Sahragard, A.; Namdari, A.; Zarshenas, M.M. Botanical Sources for Alzheimer's: A Review on Reports From Traditional Persian Medicine. Am. J. Alzheimers Dis. Other Dementias 2017, 32, $429-437$. [CrossRef] [PubMed]

25. Aggarwal, B.B.; Harikumar, K.B. Potential therapeutic effects of curcumin, the anti-inflammatory agent, against neurodegenerative, cardiovascular, pulmonary, metabolic, autoimmune and neoplastic diseases. Int. J. Biochem. Cell Biol. 2009, 41, 40-59. [CrossRef] [PubMed]

26. Alappat, L.; Awad, A.B. Curcumin and obesity: Evidence and mechanisms. Nutr. Rev. 2010, 68, 729-738. [CrossRef] [PubMed]

27. Chandran, B.; Goel, A. A randomized, pilot study to assess the efficacy and safety of curcumin in patients with active rheumatoid arthritis. Phytother. Res. 2012, 26, 1719-1725. [CrossRef] [PubMed]

28. Taylor, R.A.; Leonard, M.C. Curcumin for inflammatory bowel disease: A review of human studies. Altern. Med. Rev. 2011, 16, 152-156.

29. Shehzad, A.; Rehman, G.; Lee, Y.S. Curcumin in inflammatory diseases. Biofactors 2013, 39, 69-77. [CrossRef]

30. Tang, M.; Taghibiglou, C. The Mechanisms of Action of Curcumin in Alzheimer's Disease. J. Alzheimers Dis. 2017, 58, 1003-1016. [CrossRef]

31. Goozee, K.G.; Shah, T.M.; Sohrabi, H.R.; Rainey-Smith, S.R.; Brown, B.; Verdile, G.; Martins, R.N. Examining the potential clinical value of curcumin in the prevention and diagnosis of Alzheimer's disease. Br. J. Nutr. 2016, 115, 449-465. [CrossRef]

32. Mishra, S.; Palanivelu, K. The effect of curcumin (turmeric) on Alzheimer's disease: An overview. Ann. Indian Acad. Neurol. 2008, 11, 13-19. [CrossRef] [PubMed]

33. Nelson, K.M.; Dahlin, J.L.; Bisson, J.; Graham, J.; Pauli, G.F.; Walters, M.A. The Essential Medicinal Chemistry of Curcumin. J. Med. Chem. 2017, 60, 1620-1637. [PubMed]

34. Baker, M. Deceptive curcumin offers cautionary tale for chemists. Nature 2017, 541, 144-145. [CrossRef] [PubMed]

35. Shen, L.; Liu, C.C.; An, C.Y.; Ji, H.F. How does curcumin work with poor bioavailability? Clues from experimental and theoretical studies. Sci. Rep. 2016, 6, 20872. [CrossRef] 
36. Small, G.W.; Siddarth, P.; Li, Z.; Miller, K.J.; Ercoli, L.; Emerson, N.D.; Martinez, J.; Wong, K.P.; Liu, J.; Merrill, D.A.; et al. Memory and Brain Amyloid and Tau Effects of a Bioavailable Form of Curcumin in Non-Demented Adults: A Double-Blind, Placebo-Controlled 18-Month Trial. Am. J. Geriatr. Psychiatry 2018, 26, 266-277. [CrossRef]

37. Van Skike, C.E.; Galvan, V. A Perfect sTORm: The Role of the Mammalian Target of Rapamycin (mTOR) in Cerebrovascular Dysfunction of Alzheimer's Disease: A Mini-Review. Gerontology 2018, 64, 205-211. [CrossRef]

38. Perluigi, M.; Di Domenico, F.; Butterfield, D.A. mTOR signaling in aging and neurodegeneration: At the crossroad between metabolism dysfunction and impairment of autophagy. Neurobiol. Dis. 2015, 84, 39-49. [CrossRef]

39. Cai, Z.; Zhao, B.; Li, K.; Zhang, L.; Li, C.; Quazi, S.H.; Tan, Y. Mammalian target of rapamycin: A valid therapeutic target through the autophagy pathway for Alzheimer's disease? J. Neurosci. Res. 2012, 90, 1105-1118. [CrossRef]

40. Yang, F.; Lim, G.P.; Begum, A.N.; Ubeda, O.J.; Simmons, M.R.; Ambegaokar, S.S.; Chen, P.P.; Kayed, R.; Glabe, C.G.; Frautschy, S.A.; et al. Curcumin inhibits formation of amyloid beta oligomers and fibrils, binds plaques, and reduces amyloid in vivo. J. Biol. Chem. 2005, 280, 5892-5901. [CrossRef]

41. Tello Velasquez, J.; Watts, M.E.; Todorovic, M.; Nazareth, L.; Pastrana, E.; Diaz-Nido, J.; Lim, F.; Ekberg, J.A.; Quinn, R.J.; St John, J.A. Low-dose curcumin stimulates proliferation, migration and phagocytic activity of olfactory ensheathing cells. PLoS ONE 2014, 9, e111787. [CrossRef]

42. Ma, X.X.; Liu, J.; Wang, C.M.; Zhou, J.P.; He, Z.Z.; Lin, H. Low-dose curcumin stimulates proliferation of rat embryonic neural stem cells through glucocorticoid receptor and STAT3. CNS Neurosci. Ther. 2018, 24, 940-946. [CrossRef]

43. Akbar, M.U.; Rehman, K.; Zia, K.M.; Qadir, M.I.; Akash, M.S.H.; Ibrahim, M. Critical Review on Curcumin as a Therapeutic Agent: From Traditional Herbal Medicine to an Ideal Therapeutic Agent. Crit. Rev. Eukaryot. Gene Expr. 2018, 28, 17-24. [CrossRef]

44. Jamwal, R. Bioavailable curcumin formulations: A review of pharmacokinetic studies in healthy volunteers. J. Integr. Med. 2018, 16, 367-374. [CrossRef] [PubMed]

45. Hewlings, S.J.; Kalman, D.S. Curcumin: A Review of Its' Effects on Human Health. Foods 2017, 6, 92. [CrossRef] [PubMed]

46. Prasad, S.; Tyagi, A.K.; Aggarwal, B.B. Recent developments in delivery, bioavailability, absorption and metabolism of curcumin: The golden pigment from golden spice. Cancer Res. Treat. 2014, 46, 2-18. [CrossRef] [PubMed]

47. Teng, E.; Kepe, V.; Frautschy, S.A.; Liu, J.; Satyamurthy, N.; Yang, F.; Chen, P.P.; Cole, G.B.; Jones, M.R.; Huang, S.C.; et al. [F-18]FDDNP microPET imaging correlates with brain Abeta burden in a transgenic rat model of Alzheimer disease: Effects of aging, in vivo blockade, and anti-Abeta antibody treatment. Neurobiol. Dis. 2011, 43, 565-575. [CrossRef] [PubMed]

48. Zhang, C.; Browne, A.; Child, D.; Tanzi, R.E. Curcumin decreases amyloid-beta peptide levels by attenuating the maturation of amyloid-beta precursor protein. J. Biol. Chem. 2010, 285, 28472-28480. [CrossRef] [PubMed]

49. Van Cauwenberghe, C.; Van Broeckhoven, C.; Sleegers, K. The genetic landscape of Alzheimer disease: Clinical implications and perspectives. Genet. Med. 2016, 18, 421-430. [CrossRef]

50. Lambeth, T.R.; Riggs, D.L.; Talbert, L.E.; Tang, J.; Coburn, E.; Kang, A.S.; Noll, J.; Augello, C.; Ford, B.D.; Julian, R.R. Spontaneous Isomerization of Long-Lived Proteins Provides a Molecular Mechanism for the Lysosomal Failure Observed in Alzheimer's Disease. ACS Cent. Sci. 2019, 5, 1387-1395. [CrossRef]

51. Johnson, S.C.; Rabinovitch, P.S.; Kaeberlein, M. mTOR is a key modulator of ageing and age-related disease. Nature 2013, 493, 338-345. [CrossRef]

52. Puro, D.G.; Agardh, E. Insulin-mediated regulation of neuronal maturation. Science 1984, 225, 1170-1172. [CrossRef] [PubMed]

53. Chen, T.J.; Wang, D.C.; Chen, S.S. Amyloid-beta interrupts the PI3K-Akt-mTOR signaling pathway that could be involved in brain-derived neurotrophic factor-induced Arc expression in rat cortical neurons. J. Neurosci. Res. 2009, 87, 2297-2307. [CrossRef] [PubMed]

54. Li, L.; Zhang, S.; Zhang, X.; Li, T.; Tang, Y.; Liu, H.; Yang, W.; Le, W. Autophagy enhancer carbamazepine alleviates memory deficits and cerebral amyloid-beta pathology in a mouse model of Alzheimer's disease. Curr. Alzheimer Res. 2013, 10, 433-441. [CrossRef] [PubMed] 
55. Lafay-Chebassier, C.; Paccalin, M.; Page, G.; Barc-Pain, S.; Perault-Pochat, M.C.; Gil, R.; Pradier, L.; Hugon, J. mTOR/p70S6k signalling alteration by Abeta exposure as well as in APP-PS1 transgenic models and in patients with Alzheimer's disease. J. Neurochem. 2005, 94, 215-225. [CrossRef]

56. Kritsilis, M.; Rizou, S.V.; Koutsoudaki, P.N.; Evangelou, K.; Gorgoulis, V.G.; Papadopoulos, D. Ageing, Cellular Senescence and Neurodegenerative Disease. Int. J. Mol. Sci. 2018, 19, 2937. [CrossRef]

57. Hussain, S.P.; Hofseth, L.J.; Harris, C.C. Radical causes of cancer. Nat. Rev. Cancer 2003, 3, 276-285. [CrossRef]

58. Pinto, A.; Bonucci, A.; Maggi, E.; Corsi, M.; Businaro, R. Anti-Oxidant and Anti-Inflammatory Activity of Ketogenic Diet: New Perspectives for Neuroprotection in Alzheimer's Disease. Antioxidants 2018, 7, 63. [CrossRef]

59. Shin, Y.; Choi, S.H.; Kim, E.; Bylykbashi, E.; Kim, J.A.; Chung, S.; Kim, D.Y.; Kamm, R.D.; Tanzi, R.E. Blood-Brain Barrier Dysfunction in a 3D In Vitro Model of Alzheimer's Disease. Adv. Sci. 2019, 6, 1900962. [CrossRef]

60. Oddo, S.; Caccamo, A.; Shepherd, J.D.; Murphy, M.P.; Golde, T.E.; Kayed, R.; Metherate, R.; Mattson, M.P.; Akbari, Y.; LaFerla, F.M. Triple-transgenic model of Alzheimer's disease with plaques and tangles: Intracellular Abeta and synaptic dysfunction. Neuron 2003, 39, 409-421. [CrossRef]

61. Tsai, K.J.; Yang, C.H.; Fang, Y.H.; Cho, K.H.; Chien, W.L.; Wang, W.T.; Wu, T.W.; Lin, C.P.; Fu, W.M.; Shen, C.K. Elevated expression of TDP-43 in the forebrain of mice is sufficient to cause neurological and pathological phenotypes mimicking FTLD-U. J. Exp. Med. 2010, 207, 1661-1673. [CrossRef]

62. Wang, I.F.; Guo, B.S.; Liu, Y.C.; Wu, C.C.; Yang, C.H.; Tsai, K.J.; Shen, C.K. Autophagy activators rescue and alleviate pathogenesis of a mouse model with proteinopathies of the TAR DNA-binding protein 43. Proc. Natl. Acad. Sci. USA 2012, 109, 15024-15029. [CrossRef] [PubMed]

(C) 2020 by the authors. Licensee MDPI, Basel, Switzerland. This article is an open access article distributed under the terms and conditions of the Creative Commons Attribution (CC BY) license (http://creativecommons.org/licenses/by/4.0/). 